\title{
DAMPAK PINJAMAN DAN BANTUAN MODAL KERJA TERHADAP KINERJA USAHA Studi Kasus UMKM Binaan KADIN Jawa Tengah
}

\author{
Hoo Helena Ayu Liani; Chatarina Yekti Prawihatmi ${ }^{1)}$ \\ ${ }^{1)}$ yekti@unika.ac.id \\ Jurusan Manajemen, FEB UNIKA Soegijapranata Semarang
}

\section{Info Artikel}

Sejarah Artikel:

Diterima

Disetujui

Dipublikasikan

Keywords: MSMEs,; impact; loan; assistance, working capital; business performance

\begin{abstract}
Abstrak
Permasalahan UMKM yang selama ini dipandang utama adalah permodalan. UMKM biasanya tidak memiliki akses yang mudah untuk memperoleh pinjaman untuk modal kerja. Untuk itulah terdapat skema bantuan modal yang disediakan oleh berbagai lembaga keuangan dan lembaga pemerintah untuk mengatasi permasalahan modal di UMKM. Penelitian ini bertujuan untuk mengetahui dampak bantuan dan pinjaman modal kerja pada kinerja usaha UMKM yang dibina oleh TTIC Kadin Jawa Tengah. Responden pada penelitian ini adalah UMKM yang telah dibina oleh TTIC kadin Jawa Tengah, yang berjumlah 20 UMKM. Teknik pengumpulan data dalam penelitian ini adalah melalui wawancara mendalam dipandu dengan kuesioner. Metode penelitian pada penelitian ini adalah metode deskriptif eksploratif . Hasil penelitian ini menunjukkan bahwa bantuan / pinjaman modal kerja untuk UMKM binaan TTIC Kadin Jawa Tengah memberikan stimulus dalam usaha-usaha mengembangkan kinerja usahanya terutama dalam menambah peralatan, melakuakn inovasi , menambah tenaga kerja sampai dengan usaha perluasan pasar. Meskipun tidak secara langsung, pinjaman /bantuan modal telah berdampak positif terhadap kinerja usaha UMKM binaan TTIC Kadin Jawa Tengah.
\end{abstract}

\section{IMPACT OF LOAN AND ASSISTANCE FOR WORKING CAPITAL ON MSMES' BUSINESS PERFORMANCE Case Study on MSMEs Fostered by TTIC Kadin Jawa Tengah}

\begin{abstract}
The one of main problem of MSMEs is capital. MSMEs usually do not have easy access to obtain loans for working capital. For this reason there is a capital assistance scheme provided by various financial institutions and government agencies to address capital problems in MSMEs. This study aims to determine the impact of aid and working capital loans on the performance of SMEs business which is fostered by TTIC Kadin Jawa Tengah. Respondents in this study are MSMEs that have been fostered by TTIC Kadin Jawa Tengah. The number of respondents are 20 MSMEs. Data collection techniques in this study is through in-depth interviews guided by questionnaires. The research method in this research is descriptive explorative method. The results of this study indicate that assistance / working capital loans for MSMEs fostered by TTIC Kadin Jawa Tengah provide stimulus in the efforts to develop business performance, especially in adding equipment, making innovation, adding labor to market expansion efforts. Although indirectly, the loan / capital assistance has a positive impact on the performance of UMKM business fostered by TTIC Kadin Jawa Tengah.
\end{abstract}




\section{PENDAHULUAN}

Indonesia merupakan negara berkembang dimana perekonomiannya bukan hanya digerakkan oleh para pemodal swasta besar maupun pemerintah namun juga pemodal menengah, kecil sampai mikro yang dimana jumlahnya sangat teramat banyak dan mulai diperhitungkan. Kebijakan pemerintah untuk mendorong usaha kecil dan menengah cukup serius melalui Undang-Undang No.20 Tahun 2008 tentang Usaha Mikro,Kecil dan Menengah yang menegaskan bahwa usaha ini perlu diselenggarakan secara menyeluruh, optimal, dan berkesinambungan melalui pengembangan iklim yang kondusif, pemberian kesempatan berusaha, dukungan, perlindungan, dan pengembangan usaha seluas-luasnya (Haryadi, 2010).

Seiring dengan meningkatnya jumlah UMKM di Indonesia, begitu juga dengan peningkatan jumlah UMKM di kota Semarang.Hal ini tidak luput dari pengawasan pemerintah yaitu Dinas Koperasi dan UKM provinsi Jawa Tengah serta lembagalembaga lain dibidangnya karena peningkatan ini merupakan berita baik. Keberadaan dan peran UMKM penting dalam mewujudkan kemandirian ekonomi, UMKM merupakan sektor yang tahan terhadap krisis dan sudah terbukti saat terjadi krisis ekonomi di tahun 1998 yang lalu dimana banyak usaha besar yang gulung tikar UMKM justru bertahan dan tetap hidup. Di samping itu usaha kecil mampu menyerap tenaga kerja lebih besar karena cenderung bersifat padat karya dengan teknologi yang sederhana. Inilah yang menjadi pemicu para pemerhati ekonomi di Jawa Tengah terutama Semarang untuk melakukan pembinaan serta pengawasan pada UMKM ini agar dapat bersaing dalam pasar nasional maupun internasional.(jatengprov.go.id)

Pembinaan pada UMKM dilakukan dengan membentuk berbagai program pelatihan maupun diskusi yang bisa dilakukan kapan saja. Salah satu lembaga yang memiliki program pembinaan UMKM ialah TTIC (Trade,Training and Information Center) oleh Kadin Jawa tengah. Latar belakang terbentuknya TTIC sendiri ialah sebagai unit taktis Kadin Jateng yang mampu memberikan manfaat langsung dan nyata bagi anggotanya dalam rangka membangun citra dan kinerja Kadin Jateng sebagai mitra pembangunan pemerintah yang utama,serta semangat ekonomi mandiri yang menjadi dasar pengembangan dan pembinaan UMKM serta tak luput juga ibukota Jawa Tengah, Semarang.

Program milik TTIC mengenai UMKM tersebut bernama Rumah UMKM yang dapat diakses melalui 3 jalur yaitu internet,mendatangi kantor Kadin ataupun UMKM center di Banyumanik,Semarang. Rumah UMKM adalah sebuah program pembinaan dan pengembangan UMKM yang didedikasikan oleh unit TTIC Kamar Dagang dan Industri Provinsi Jawa Tengah(organisasi non profit) kepada pelaku UMKM di Provinsi Jawa Tengah.Rumah UMKM merupakan wadah bagi komunitas UMKM Jawa Tengah untuk membangun komunikasi,organisasi dan jaringan pemasaran produk UMKM.TTIC Kadin Jateng pun melakukan pembinaan dari sisi keuangan atau modal 
untuk membantu para pelaku usaha mikro untuk bisa mendapatkan bantuan modal kerja dari lembaga keuangan perbankan maupun non perbankan. Maka dalam penelitian ini akan dibahas mengenai dampak bantuan dan pinjaman modal bagi kinerja usaha UMKM binaan TTIC Kadin Jawa Tengah.

\section{TELAAH PUSTAKA}

\section{Definisi Bantuan dan Pinjaman Modal Kerja}

Menurut Kamus Bahasa Indonesia, bantuan dan pinjaman modal kerja memiliki pengertian yang berbeda. Namun antara bantuan dan pinjaman memiliki memiliki fungsi yang sama. Bantuan modal kerja didefinisikan sebagai pinjaman modal yang syarat-syaratnya lunak, seperti bisa tanpa agunan, bunga pinjaman lebih rendah, prosedur dan persyaratan lebih mudah dan waktu pengembalian lebih lama. Biasanya seleksi untuk memperoleh bantuan modal lebih ketat dibandingkan seleksi untuk memperoleh pinjaman modal. Sementara pinjaman modal menunjuk pada pinjaman dengan syarat-syarat yang berlaku pada umumnya, besarnya bunga pinjaman juga adalah bunga komersial, diperoleh dengan memenuhi ketentuan lembaga keuangan perbankan atau non perbankan.

\section{Modal Kerja}

Menurut Kamus Besar Bahasa Indonesia modal kerja ialah bagian modal yang beredar dl jangka waktu pendek, yaitu beredar dari uang menjadi persediaan barang piutang dan menjadi uang kembali. Sedangkan modal dalam arti uang yang dipakai sebagai pokok (induk) untuk berdagang,harta benda (uang, barang, dan sebagainya) yang dapat dipergunakan untuk menghasilkan sesuatu yang menambah. Menurut Sawir (2003) modal kerja adalah keseluruhan aktiva lancar yang dimiliki perusahaan,atau dapat pula dimaksudkan sebagai dana yang harus tersedia untuk membiayai kegiatan operasi perusahaan sehari-hari.Modal kerja memiliki beberapa teori mengenai konsep modal kerja seperti yang disebutkan Riyanto dalam bukunya,konsepnya antara lain:

\section{Konsep kuantitatif}

Modal kerja dalam konsep kuantitatif adalah sejumlah dana yang tertanam dalam aktiva lancar berupa kas,piutang dan pesrediaan.Dana yang tertanam dalam aktiva lancar akan mengalami perputaran dalam waktu yang pendek.Dengan demikian modal kerja menurut konsep ini adalah keseluruhan dari jumlah aktiva lancar yang dimiliki atau dapat disebut juga modal kerja bruto(gross working capital)

\section{Konsep kualitatif}

Menurut konsep ini modal kerja adalah aktiva lancar yang sungguh masih dapat digunakan untuk membiayai operasional perusahaan tanpa mengganggu likuiditasnya yaitu yang merupakan kelebihan aktiva lancar atas utang lancarnya.

\section{Konsep fungsional}

Konsep ini mendasarkan pada fungsi dari dana dalam menghasilkan pendapatan.Setiap dana yang digunakan dalam perusahaan secara umum dimaksudkan untuk menghasilkan pendapatan. 


\section{Faktor YangMempengaruhi Jumlah Modal Kerja}

Faktor-faktor yang mempengaruhi jumlah modal kerja yaitu:

a) Sifat umum atau tipe perusahaan.

Modal kerja yang dibutuhkan perusahaan jasa (public utility) relatif rendah karena investasi dalam persediaan dan piutang pencairannya menjadikan relatif cepat.

b) Waktu yang diperlukan untuk memproduksi atau mendapatkan barang dan ongkos produksi per unit atau harga beli per unit barang. Jumlah modal kerja bukan langsung dengan waktu yang dibutuhkan mulai dari bahan baku atau barang jadi dibeli sampai barang-barang dijual kepada langganan. Makin panjang waktu yang diperlukan untuk memproduksi barang atau untuk memperoleh barang makin besar kebutuhan akan modal kerja.

c) Syarat pembelian dan penjualan

Syarat kredit pembelian barang dagangan atau bahan baku akan mempengaruhi besar kecilnya modal kerja

d) Tingkat perputaran persediaan.

Semakin sering persediaan diganti (dibeli dan dijual kembali) maka kebutuhan modal kerja yang ditanamkan dalam bentuk persediaan (barang) akan semakin rendah.

e) Tingkat perputaran piutang

Kebutuhan modal kerja juga tergantung pada periode waktu yang diperlukan untuk mengubah piutang menjadi uang kas.

f) Pengaruh konjungtur (business cycle)

Pada periode makmur (prosperity) aktivitas perusahaan meningkat dan perusahaan cenderung membeli barang lebih memanfaatkan harga yang masih rendah. Ini berarti perusahaan memperbesar tingkat persediaan. Peningkatan jumlah persediaan membutuhkan modal kerja yang lebih banyak. Sebaiknya dalam periode depresi volume perdagangan menurun, perusahaan cepat-cepat berusaha menjual barangnya dan menarik piutangnya. Uang yang di peroleh digunakan untuk membeli surat-surat berharga, melunasi utang, atau untuk menutupi kerugian.

g) Derajat risiko kemungkinan menurunnya harga jual aktiva jangka pendek menurunya nilai riil dibanding dengan harga buku dari surat-surat berharga, persediaan barang, dan piutang akan menurunkan modal kerja.

h) Pengaruh musim

Banyak perusahan yang penjualannya hanya terpusat pada beberapa bulan saja. Perusahaan yang di pengaruhi oleh musim membutuhkan jumlah maksimum 
modal kerja untuk periode yang relatif pendek. Modal kerja yang ditanamkan dalam bentuk persediaan barang berangsur-angsur meningkat dalam bulan-bulan menjelang puncak penjualan.

i) Credit rating dari perusahaan

Jumlah modal kerja, dalam bentuk kas termasuk surat-surat berharga, yang dibutuhkan perusahaan untuk membiayai opersinya tergantung pada kebijaksanaan penyediaan uang kas. Penyediaan uang kas ini tergantung pada: (a) credit rating dari perusahaan (kemampuan meminjam uang dalam jangka pendek), (b) perputaran persediaan dan piutang,dan (c) kesempatan mendapatkan potongan harga dalam pembelian.

\section{Sumber Modal Kerja}

Modal kerja dapat diperoleh dari berbagai contoh yakni sebagai berikut : a) Pendapatan bersih, 2) Keuntungan dari penjualan surat berharga, 3) Penjualan aktiva tetap,investasi jangka panjang dan aktiva tidak lancar lainnya, 4) Penjualan obligasi dan saham, 5) Dana pinjaman dari bank dan pinjaman jangka pendek lainnya, 6) Kredit dari supplier

\section{Kredit atau Pinjaman}

Pengertian kredit menurut UU No. 7 tahun 1992 tentang perbankan sebagaimana telah diubah dengan UU No. 10 tahun 1998 adalah penyediaan uang atau tagihan yang dapat dipersamakan dengan itu bedasarkan persetujuan atau kesepakatan pinjam meminjam antara bank dengan pihak lain yang mewajibkan pihak peminjam untuk melunasi utangnya setelah jangka waktu tertentu dengan jumlah bunga, imbalan atau pembagian hasil keuntungan.(bi.go.id). Kredit memiliki beberapa jenis menurut fungsi dan sifatnya yaitu antara lain:Kredit investasi, Kredit modal kerja (ekspor,pertokoan.pabrik,makanan/minuman,industry), Kredit perdagangan, Kredit produktif, Kredit konsumtif dan Kredit profesi

Unsur-unsur yang terkandung dalam pemberian fasilitas kredit adalah sebagai berikut: (1) Adanya badan,organisasi atau perorangan yang memiliki uang,barang atau jasa yang bersedia untuk meminjamkan kepada pihak pemohon/lain,orang atau barang demikian lazim disebut kreditur; (2) Adanya pihak yang meminjam sejumlah uang maupun barang atau jasa disebut debitur; (3) Adanya kepercayaan dari kreditur terhadap debitur; (4) Adanya janji atau kontrak bayar membayar dari debitur kepada kreditur; (5) Adanya perbedaan waktu yaitu antara waktu saat penyerahan uang,barang,jasa oleh kreditur dengan saat pembayaran kembali dari debitur; (6) Terdapat resiko yaitu sebagai akibat dari adanya perbedaan waktu seperti diterangkan diatas,dimana masa yang akan datang merupakan sesuatu yang belum pasti,maka kredit itu pada dasarnya mengandung resiko,misal penurunan nilai uang karena inflasi dan sebagainya; (7) Terdapat bunga yang ditetapkan dan harus dibayar oleh debitur kepada kreditur (Firdaus,2009)

\section{Jenis-jenis Pinjaman atau Kredit}

Kredit memiliki beberapa sifat dan jenis yang digolongkan demi mempermudah proses pencairan atau penentuan jatuh tempo dan sebagainya,maka dibawah ini dijabarkan penggolongan jenis-jenis kredit. Menurut Dahlan (1999), kredit ini dapat digolongkan ke dalam enam bentuk yaitu: 
1. Penggolongan kredit berdasarkan jangka waktu (maturity), antara lain:

a. Kredit jangka pendek (shot-term loan)

b. Kredit jangka menengah (medium-term loan)

c. Kredit jangka panjang (long-em loan)

2. Penggolongan kredit berdasarkan barang jaminan (collateral), antara lain:

a. Kredit dengan jaminan (secured loan)

b. Kredit dengan jaminan (unsecured loan)

3.Kredit berdasarkan segmen usaha, seperti otomotif, pharmasi, tekstil, makanan,konstruksi dan sebagainya.

4. Penggolongan kredit berdasarkan tujuannya, antara lain:

a. Kredit komersil (commercial loan), yaitu kredit yang diberikan untuk memperlancar kegiatan usaha nasabah di bidang perdagangan.

b. Kredit konsumtif (consumer loan), yaitu kredit yang diberikan untuk memenuhi kebutuhan debitur yang bersifat konsumtif.

c. Kredit produktif (productive loan), yaitu kredit yang diberikan dalam rangka membiayai kebutuhan modal kerja debitur sehingga dapat memperlancar produksi.

5. Penggolongan kredit menurut penggunaannya, antara lain:

a. Kredit modal kerja (working capital credit), yaitu kredit yang diberikan oleh bank untuk menambah modal kerja debitur.

b. Kredit investasi (Invesment credit), yaitu kredit yang diberikan kepada perusahaan untuk digunakan melakukan investasi dengan membeli barang-barang modal.

6. Kredit non kas (non cash loan), yaitu kredit yang diberikan kepada nasabah yang hanya boleh ditarik apabila suatu transaksi yang telah diperjanjikan telah direalisasikan atau efektif.

\section{Penelitian Terdahulu}

Penelitian terdahulu ini dicantumkan guna menggali informasi tentang ruang penelitian yang berkaitan dengan penelitian ini. Berdasarkan penelusuran dari penelitian terdahulu ditemukan terdapat perbedaan dampak bantuan modal terhadap kinerja usaha UMKM seperti yang ditunjukkan pada tabel 2.1. 
Tabel 2.1

\section{Penelitian Terdahulu}

\begin{tabular}{|c|c|c|c|c|}
\hline No. & $\begin{array}{l}\text { Judul,Peneliti dan Tahun } \\
\text { Penelitian }\end{array}$ & Variabel & $\begin{array}{l}\text { Metode } \\
\text { Analisis }\end{array}$ & Hasil penelitian \\
\hline 1. & $\begin{array}{l}\text { Analisis Pengembangan } \\
\text { Usaha UKM Setelah } \\
\text { Mendapatkan Modal } \\
\text { Usaha Ekonomi Produktif } \\
\text { di Kabupaten Tegal,Oke } \\
\text { Setiarso,2009 }\end{array}$ & $\begin{array}{l}\text { Perspektif } \\
\text { keuangan,pers } \\
\text { pektif } \\
\text { pemasaran,per } \\
\text { spektif bisnis } \\
\text { internal }\end{array}$ & $\begin{array}{l}\text { Analisis } \\
\text { deskriptif,ana } \\
\text { lisis } \\
\text { Tabulasi,Uji } \\
\text { MC } \\
\text { Nemar(analis } \\
\text { is } \\
\text { komparatif) }\end{array}$ & $\begin{array}{l}\text { Variabel bantuan } \\
\text { Pengembangan Usaha } \\
\text { Ekonomi Produktif(PUEP) } \\
\text { tidak memiliki pengaruh } \\
\text { yang berarti bagi } \\
\text { peningkatan kinerja } \\
\text { keuangan(laba usaha) } \\
\text { UKM di Kabupaten } \\
\text { Tegal,hanya sebatas } \\
\text { peningkatan volume } \\
\text { penjualan,tetapi tidak } \\
\text { diikuti dengan peningkatan } \\
\text { jangkauan pemasaran. }\end{array}$ \\
\hline 2. & $\begin{array}{l}\text { Efektivitas Pelaksanaan } \\
\text { Program Pengembangan } \\
\text { Usaha Mikro Kecil Dan } \\
\text { Menengah } \\
\text { Usaha Mikro Kecil } \\
\text { Menengah) ( Suatu Studi } \\
\text { Di Dinas Koperasi, Usaha } \\
\text { Mikro, Kecil. } \\
\text { Dan Menegah Kota } \\
\text { Manado),Suryaningrum;p } \\
\text { angkey;kyai,2015 }\end{array}$ & $\begin{array}{l}\text { Efektivitas } \\
\text { produksi,efisie } \\
\text { nsi,kepuasan,a } \\
\text { daptasi dan } \\
\text { pengembangan }\end{array}$ & $\begin{array}{l}\text { Analisis } \\
\text { deskriptif } \\
\text { kualitatif }\end{array}$ & $\begin{array}{l}\text { Di ukur dengan indikator } \\
\text { produksi,efisiensi,kepuasa } \\
\text { n,adaptasi dan } \\
\text { pengembangan, } \\
\text { program-program } \\
\text { pengembangan } \\
\text { UMKM oleh Dinas } \\
\text { Koperasi dan } \\
\text { UMK Kota Manado } \\
\text { sudah berjalan } \\
\text { Efektif }\end{array}$ \\
\hline 3. & $\begin{array}{l}\text { Dampak Program Dana } \\
\text { Bergulir Bagi Usaha } \\
\text { Kecil dan Menengah } \\
\text { (UKM), Achma Hendra } \\
\text { dan Tri Wahyu,2009 }\end{array}$ & $\begin{array}{l}\text { Tenaga } \\
\text { Kerja,Modal } \\
\text { Usaha,Omzet } \\
\text { Penjualan,Keu } \\
\text { ntungan }\end{array}$ & $\begin{array}{l}\text { Uji korelasi } \\
\text { parsial,Analis } \\
\text { is Deskriptif } \\
\text { dan uji } \\
\text { pangkat tanda } \\
\text { Wilcoxon }\end{array}$ & $\begin{array}{l}\text { bantuan pinjaman atau } \\
\text { dana perkuatan bagi } \\
\text { usaha mandiri UKM } \\
\text { mampu menambah jumlah } \\
\text { tenaga kerja, modal } \\
\text { usaha,omset penjualan, dan } \\
\text { keuntungan. Dari keempat } \\
\text { variabel tersebut,kenaikan } \\
\text { tenaga kerja memiliki } \\
\text { perbedaan yang paling } \\
\text { besar antara sebelum dan } \\
\text { sesudah menerima bantuan } \\
\text { perkuatan }\end{array}$ \\
\hline 4. & $\begin{array}{l}\text { Studi Eksplorasi } \\
\text { Pembiayaan Usaha Kecil } \\
\text { Dan Menengah } \\
\text { (Ukm) Di Sentra-Sentra } \\
\text { Industri Kecil Di Jawa } \\
\text { Timur,Ely Siswanto,2012 }\end{array}$ & $\begin{array}{l}\text { Pembiayaan } \\
\text { usaha } \\
\text { mikro,kecil } \\
\text { dan } \\
\text { menengah,kar } \\
\text { akteristik } \\
\end{array}$ & $\begin{array}{l}\text { Analisis } \\
\text { deskriptif } \\
\text { eksploratif }\end{array}$ & $\begin{array}{l}\text { Pembiayaan tidak mutlak } \\
\text { dalam bentuk pinjaman } \\
\text { modal melainkan dapat } \\
\text { berbentuk barang modal } \\
\text { yang biasanya disediakan } \\
\text { pelanggan atau }\end{array}$ \\
\hline
\end{tabular}




\begin{tabular}{|l|l|l|}
\hline & $\begin{array}{l}\text { pengusaha,mo } \\
\text { del } \\
\text { pembiayaan }\end{array}$ & \\
& $\begin{array}{l}\text { supplier,yang terpenting } \\
\text { adalah bagaimana } \\
\text { memperluas pasar dan } \\
\text { meningkatkan volume } \\
\text { penjualan karna } \\
\text { mempengaruhi permintaan } \\
\text { produk yang } \\
\text { mempermudah pengusaha } \\
\text { memperoleh } \\
\text { pinjaman,model } \\
\text { pembiayaan di sentra usaha } \\
\text { kecil . }\end{array}$ \\
\hline
\end{tabular}

Sumber; literatur review

\section{METODE}

Objek dalam penelitian ini adalah usaha mikro,kecil dan menengah yang dibina dan terdaftar di TTIC Kadin Jawa Tengah pada tahun 2013-2016. Populasi dalam penelitian ini ialah UMKM yang masih aktif dan terdaftar pada TTIC Kadin Jawa tengah yang berlokasi di Semarang,Jawa Tengah. Sampel dalam penelitian ini dipilih dengan menggunakan metodepurposive random samplingyaitu metode pengambilan sampel acak berdasarkan kriteria tertentu. Kriteria-kriteria yang ditentukan dalam pengambilan sampel yaitu: a) Usaha Mikro Kecil dan Menengah yang terdaftar di TTIC Kadin Jawa Tengah dan dibina oleh TTIC Kadin Jawa Tengah; b) Usaha Mikro Kecil dan Menengah yang bergerak dalam bidang manufaktur atau industri dikarenakan banyak yang lebih memenuhi kriteria atau skala perusahaan sebagai umkm; c) UMKM yang berlokasi di Semarang .

Tabel 1

Daftar Responden : UMKM yang dibina TTIC Kadin Jawa Tengah

\begin{tabular}{|c|c|c|c|c|}
\hline No. & $\begin{array}{l}\text { Nama } \\
\text { Perusahaan }\end{array}$ & $\begin{array}{l}\text { Nama } \\
\text { pemilik }\end{array}$ & Produk & Alamat/Telepon \\
\hline 1. & $\begin{array}{l}\text { Conneta } \\
\text { Chocolate }\end{array}$ & Leni Arjani & $\begin{array}{l}\text { Coklat stick dan } \\
\text { coklat bar }\end{array}$ & $\begin{array}{l}\text { Pekunden Dalam 47,Semarang- } \\
0816660248\end{array}$ \\
\hline 2. & Cilukbatik & Christin & Batik Anak & $\begin{array}{l}\text { 0818451447,Instagram:cilukbatik,cil } \\
\text { ukbatik@gmail.com }\end{array}$ \\
\hline 3. & Lunpia King & $\begin{array}{l}\text { M.Eddy } \\
\text { Arissiato }\end{array}$ & Lunpia & $\begin{array}{l}\text { Jl.Selomas Timur IX/433,Semarang- } \\
091914490004\end{array}$ \\
\hline 4. & $\begin{array}{l}\text { Rumah sehat } \\
\text { nugget dan } \\
\text { Ganyong }\end{array}$ & Maria & $\begin{array}{l}\text { Nugget } \\
\text { ganyong,brownies } \\
\text { kukus } \\
\text { ganyong,dawet } \\
\text { ganyong }\end{array}$ & $\begin{array}{l}\text { Jl.Bukit Limau VI blok F,B-8 } \\
\text { Ngaliyan }\end{array}$ \\
\hline 5. & Bungas & Retno & $\begin{array}{l}\text { Tas kain tektur } \\
\text { karung }\end{array}$ & Jl. ParangKusumo7/72 Tlogosari \\
\hline 6. & $\begin{array}{l}\text { Bandeng } \\
\text { Mutiara Hati }\end{array}$ & $\begin{array}{l}\text { Mujiati } \\
\text { Narni }\end{array}$ & $\begin{array}{l}\text { Bandeng } \\
\text { presto,otak-otak }\end{array}$ & $\begin{array}{l}\text { Jl.Gatot Subroto RT 04/RW } 04 \\
\text { Babankerep Ngaliyan,Semarang- }\end{array}$ \\
\hline
\end{tabular}




\begin{tabular}{|c|c|c|c|c|}
\hline & & & bandeng & 085712065249 \\
\hline 7. & Ken's & Suartiah & Lunpia & $\begin{array}{l}\text { Jl.Batan Sawo I/24,Semarang- } \\
085101611567 / 02470611567\end{array}$ \\
\hline 8. & Enamura & Sri Ratnasih & Layur Crispy & $\begin{array}{l}\text { JL.Parangkusumo } 12 \text { no.33 } \\
\text { Tlogosari,Semarang-024 } 70406614\end{array}$ \\
\hline 9. & $\begin{array}{l}\text { UD.Makmur } \\
\text { Mandiri }\end{array}$ & $\begin{array}{l}\text { Rahayunings } \\
\text { ih }\end{array}$ & Tahu Bakso & $\begin{array}{l}\text { J1.Purwosari IV no. } 23 \text { kaligawe } \\
\text { semarang }\end{array}$ \\
\hline 10. & $\begin{array}{l}\text { Wingko Wijen } \\
\text { Evita }\end{array}$ & Evyloadinata & Wingko wijen & $\begin{array}{l}\text { Jl.Dr Wahidin no.16,Semarang-024 } \\
700070098\end{array}$ \\
\hline 11. & Maknyuss & $\begin{array}{l}\text { Siti } \\
\text { Rochanah }\end{array}$ & Ikan Crispy & $\begin{array}{l}\text { J.Tawangsari Utara no.70,Semarang- } \\
02433141945\end{array}$ \\
\hline 12. & Efata & $\begin{array}{l}\text { Trifena } \\
\text { Lisalio }\end{array}$ & Sambal Pecel & $\begin{array}{l}\text { JL.Kualamas XIII/646,Semarang- } \\
081805853932\end{array}$ \\
\hline 13. & Pia'ku & $\begin{array}{l}\text { Yuliana } \\
\text { Susri } \\
\text { Sudaryatni }\end{array}$ & $\begin{array}{l}\text { Bakpia kacang } \\
\text { hijau }\end{array}$ & $\begin{array}{l}\text { Jl.Taman Karonsih Selatan II/523 } \\
\text { Ngaliyan,Semarang-082221805137 }\end{array}$ \\
\hline 14. & $\begin{array}{l}\text { Daffa Dry } \\
\text { Snacks }\end{array}$ & Dwi Fitriani & Cheesestick & $\begin{array}{l}\text { Jl.Mijen Permai B/13,Semarang-024 } \\
76672565\end{array}$ \\
\hline 15. & $\begin{array}{l}\text { Sambel Sedep } \\
\text { Oma }\end{array}$ & $\begin{array}{l}\text { Felicia } \\
\text { Wenny } \\
\text { Wicaksono }\end{array}$ & Sambel Matang & $\begin{array}{l}\text { Jl. Karang Kojo Selatan } 432 \text { G } \\
\text { Semarang- } 0816669720 / \\
087832421852\end{array}$ \\
\hline 16. & $\begin{array}{l}\text { Cv.BPOI Indo } \\
\text { Jaya }\end{array}$ & Inez & Kaos sablon & Jl. Veteran no.47,Semarang \\
\hline 17. & $\begin{array}{l}\text { Nuri Kreasi } \\
\text { Mandiri }\end{array}$ & Riyanto & $\begin{array}{l}\text { Label dan } \\
\text { Merchandise } \\
\text { Rubber }\end{array}$ & $\begin{array}{l}\text { Perum Dolog L-190 RT/RW 08/01 } \\
\text { kel. Tlogosariwetan Kec. } \\
\text { Pedurungan Semarang- } \\
08158907287,082134021515\end{array}$ \\
\hline 18. & Palupi Craft & Marthania & $\begin{array}{l}\text { Kerajinan kulit } \\
\text { kombinasi batik } \\
\text { dan tenun yang } \\
\text { berfokus pada } \\
\text { produksi } \\
\text { tas, dompet }\end{array}$ & $\begin{array}{l}\text { Perumahan Graha Mutiara, } \\
\text { Jl. Tlogo Mukti Raya Blok B No 1- } \\
2 \text { Tlogosari,Semarang- } \\
081215556090\end{array}$ \\
\hline 19. & Happy Plaster & $\begin{array}{l}\text { Irwan } \\
\text { Kurniadi }\end{array}$ & $\begin{array}{l}\text { Happy plaster } \\
\text { painting kit dan } \\
\text { kids education } \\
\text { toys }\end{array}$ & $\begin{array}{l}\text { Plamongan Indah blok } \\
\text { C15/NO.10,Semarang-024 } 76737185\end{array}$ \\
\hline 20 & Ranis & Anis & Tas handmade & $\begin{array}{l}\text { Jl.Menoreh Tengah III no.32 } \\
\text { Sampangan Gajahmungkur- } \\
\text { Semarang }\end{array}$ \\
\hline
\end{tabular}

Sumber; Kadin Jawa Tengah

Jenis penelitian yang digunakan pada penelitian ini bersifat deskriptif eksploratif ,dimana peneliti hendak mengetahui dampak bantuan dan pinjaman modal modal kerja terhadap kinerja usaha UMKM Binaan TTIC Kadin yang meliputi omset penjualan dan laba usaha Kecil dan Menengah. Dengan demikian melalui penelitian deskriptif eksploratof ini hanya berusaha menggambarkan permasalahan atau dilema yang muncul dalam kaitannya pembiayaan pada UMKM yang terdaftar dan dibina oleh TTIC Kadin Semarang Jawa Tengah. Dalam penelitian ini peneliti menggunakan data primer sebagai sumber data penelitian.Data primer diperoleh dengan cara: 1) wawancara mendalam, yaitu melakukan tanya jawab kepada pelaku usaha mikro mengacu pada kuesioner yang sudah disiapkan yang tentunya berkaitan dengan pembiayaan atau pengelolaan modal saat mendapat bantuan modal dari pemerintah atau badan keuangan lain seperti bank; 2) Observasi dengan melakukan pengamatan 
langsung dari seluruh responden terhadap gejala atau fenomena yang diteliti guna memperdalam data yang diperoleh melalui wawancara. Metode analisis data yang digunakan peneliti dalam penelitian ini adalah analisa deskriptif eksploratif.

\section{HASIL DAN PEMBAHASAN Profil Responden}

Jumlah responden yang memenuhi kriteria sampel dalam penelitian ini berjumlah 20 UMKM. Sebanyak $65 \%$ responden memiliki usaha yang bergerak pada industri makanan atau minuman dan $35 \%$ responden bergerak pada usaha pakaian yaitu baju batik ,kaos sablon dan handycraft.Menurut permodalannya, sebanyak 35\% responden memiliki modal antara Rp 3.000.000,00-20.000.000,00 dan 20\% memiliki modal lebih dari Rp 20.000.000. berdasarkan sumber permodalannya, $80 \%$ modal berasal dari pribadi ditambah dengan bantuan dan pinjaman. Sebesar $70 \%$ dari responden yang diteliti memiliki sistem pembukuan, meskipun masih sederhana seperti alur kas,HPP,rugi laba dan neraca. Kemampuan dalam membuat pembukuan dimiliki oleh para responden melalui :1) adanya pengalaman usaha atau kerja, 2) pernah belajar saat sekolah atau kuliah, 3) adanya pelatihan yang diberikan oleh pihak pembina seperti TTIC Kadin dan Dinas Koperasi dan UKM.

Menurut jumlah tenaga kerjanya , $15 \%$ dari responden mempekerjakan karyawan diatas 5 orang,dan 65\% lainnya cukup dengan mempekerjakan kurang dari 5 orang karyawan untuk usahanya. Dalam hal pembayaran gaji karyawan,tidak sedikit yang menggunakan model pembayaran borongan yang dimaksud adalah karyawan digaji harian,mingguan atau bulanan berdasar jumlah barang yang selesai dikerjakan.Hanya beberapa UMKM yang mampu membayar karyawannya secara bulanan dengan nominal sebesar UMR area Semarang.

\section{Akses Pinjaman dan bantuan modal}

Modal merupakan syarat penting yang harus dimiliki untuk menjalankan kegiatan produksi. Ketika modal sendiri terbatas atau bahkan kurang untuk memulai usaha atau mengembangkan usaha, UMKM memerlukan tambahan modal dari sumber lain. UMKM Binaan TTIC kadin Jawa Tengah ini mendapat pembinaan pengelolaan keuangan dan pembukuan usaha sehingga dapat memiliki akses terhadap permodalan dari perbankan. Hasil pelatihan pengelolaan keuangan dan pembukuan pada UMKM Binaan TTIC kadin Jawa Tengah telah mampu membantu UMKM mendapatkan pinjaman maupun bantuan modal dari BRI, Bank Mandiri dan Dinas Koperasi dan UMKM. Tambahan modal baik yang berupa pinjaman, bantuan atau hibah dirasakan oleh sebagian besar responden memberikan suntikan untuk usahanya. Sebagian besar responden yaitu sebesar $70 \%$ responden telah berhasil memperoleh tambahan modal dari lembaga keuangan maupun lembaga pemerintah tersebut. 
Tabel 2.

Sumber dan Jumlah Bantuan/Pinjaman Modal Kerja

\begin{tabular}{|c|c|c|c|}
\hline No & $\begin{array}{c}\text { Nama } \\
\text { UMKM }\end{array}$ & Sumber Bantuan & $\begin{array}{c}\text { Jumlah } \\
\text { Bantuan/Pinjaman }\end{array}$ \\
\hline 1 & Bungas & Bank Indonesia & Rp 17.500.000,00 \\
\hline 2 & $\begin{array}{l}\text { CV BPOI Indo } \\
\text { Jaya }\end{array}$ & Bank Rakyat Indonesia & $\operatorname{Rp} 25.000 .000,00$ \\
\hline 3 & Prisma Food & Bank Jateng & $\begin{array}{l}\operatorname{Rp} 30.000 .000,00 \\
\operatorname{Rp} 15.000 .000,00\end{array}$ \\
\hline 4 & $\begin{array}{l}\text { Nuri Kreasi } \\
\text { Mandiri }\end{array}$ & Bank Mandiri & $\operatorname{Rp} 50.000 .000,00$ \\
\hline 5 & Fadia food & Bank Rakyat Indonesia & Rp 10.000.000,00 \\
\hline 6 & Ranis & Bank Indonesia & Rp 15.000.000,00 \\
\hline 7 & Ciluk Ba batik & Bank Mandiri & $\operatorname{Rp} 25.000 .000,00$ \\
\hline 8 & $\begin{array}{l}\text { Cornetta } \\
\text { Chocolate }\end{array}$ & Bank Rakyat Indonesia & $\operatorname{Rp} 25.000 .000,00$ \\
\hline 9 & Lunpia King & $\begin{array}{c}\text { Dinas Koperasi dan } \\
\text { UMKM }\end{array}$ & Rp 5.000.000,00 \\
\hline 10 & Kens & $\begin{array}{c}\text { Dinas Koperasi dan } \\
\text { UMKM }\end{array}$ & Rp 5.000.000,00 \\
\hline 11 & Enamura & $\begin{array}{c}\text { Dinas Koperasi dan } \\
\text { UMKM }\end{array}$ & Rp 5.000.000,00 \\
\hline 12 & $\begin{array}{l}\text { Wingko Wijen } \\
\text { Evita }\end{array}$ & $\begin{array}{c}\text { Dinas Koperasi dan } \\
\text { UMKM }\end{array}$ & Rp 5.000.000,00 \\
\hline 13 & Palupi Craft & Bank Jateng & $\operatorname{Rp} 25.000 .000,00$ \\
\hline 14 & Happy Plaster & Bank Jateng & $\operatorname{Rp} 25.000 .000,00$ \\
\hline
\end{tabular}

\section{Permasalahan yang dihadapi dalam Pengajuan Bantuan/Pinjaman Modal Kerja}

Tidak semua UMKM Binaan TTIC Kadin Jawa Tengah bersedia mengajukan bantuan atau pinjaman modal kerja atau sudah mengajukan namun belum berhasil mendapatkan bantuan ataupun pinjaman modal kerja. Beberapa alasan dan permasalahan dalam pengajuan bantuan/pinjaman modal kerja tersebut adalah sebagai berikut; 
Tabel 3.

\section{Alasan dan Permasalahan Yang Menyebabkan Tidak/belum Memperoleh Bantuan/Pinjaman Modal Kerja}

\begin{tabular}{|l|l|}
\hline ALASAN/PERMASALAHAN & \multicolumn{1}{|c|}{ KETERANGAN } \\
\hline Malas membayar bunga cicilan & $\begin{array}{l}\text { Beban cicilan dikenakan bunga dan pembayaran } \\
\text { dilakukan dalam periode yang sudah } \\
\text { ditentukan.Dirasa membebani dalam hal biaya(bunga) } \\
\text { dan beban pikiran }\end{array}$ \\
\hline Agunan terlalu berat & $\begin{array}{l}\text { Agunan atau jaminan berupa sertifikat tanah,BPKP } \\
\text { kendaraan,dsb }\end{array}$ \\
\hline $\begin{array}{l}\text { Syarat pengajuan tidak dapat } \\
\text { dipenuhi }\end{array}$ & $\begin{array}{l}\text { Perusahaan minimal memiliki 3 orang tenaga } \\
\text { kerja,berbadan hukum minimal CV }\end{array}$ \\
\hline Ditolak oleh pihak perbankan & Tidak memenuhi syarat atau dirasa tidak bonafit \\
\hline Belum membutuhkan & $\begin{array}{l}\text { Responden merasa cukup dengan modal sendiri } \\
\text { sehingga usaha berkembang secara perlahan tidak } \\
\text { secara drastis }\end{array}$ \\
\hline
\end{tabular}

Sumber; hasil wawancara

\section{Dampak Bantuan/Pinjaman Modal Kerja Terhadap Kinerja Usaha UMKM}

Banyak faktor yang mempengaruhi kinerja keuangan sebuah usaha terutama modal kerja untuk operasional usaha. Modal operasional usaha cenderung mengarah kepada alat-alat produksi, tempat produksi,kemasan produk, perlengkapan, persediaan bahan baku dan lainnya.. Bantuan modal atau pinjaman modal kerja sangat membantu UMKM Binaan TTIC kadin jateng untuk mengembangkan usaha. Bantuan atau pinjaman modal digunakan UMKM untuk meningkatkan jumlah produksi dan melakukan inovasi produk. UMKM yang menjual produk non makanaN, jika akan menjual sebuah produk maka harus harus memberikan penawaran berupa contoh atau display barang jadi dimana akan menjadi acuan konsumen dalam mengajukan permintaan. Dalam melakukan penawaran dibutuhkan dana untuk membuat produk tersebut terlebih dahulu. Berbeda dengan sistem pre-order yang mewajibkan konsumen membayar uang muka atau pembayaran lunas sebelum konsumen mendapatkan barang yang diinginkan.Disini modal dalam bentuk uang tidak terlalu dipermasalahkan karena si empunya usaha hanya perlu memutarkan uang itu kepada supplier.

Pengalokasian bantuan atau pinjaman modal oleh UMKM adalah untuk meningkatkan produksi seperti memilih bahan baku dengan kualitas lebih baik atau memperbanyak tenaga kerja agar hasil produksi dapat lebih maksimal secara kuantitas dan kualitasnya. Sebagian besar UMKM menggunakan pinjaman tersebut untuk mendanai sarana dan prasarana yang mereka yakini bahwa apabila memiliki sarana prasarana yang baik maka aspek lainpun secara sadar atau tidak sadar akan ikut meningkat.Yang dimaksud dengan sarana prasarana ialah mencakup alat operasional seperti mesin jahit,oven,mesin bubut,kendaraan bermotor,tempat usaha yang layak,dan sebagainya. Beberapa UMKM juga menggunakan bantuan atau pinjaman modal untuk menambah kas usaha. Dalam hal ini, UMKM menggunakan dana tersebut untuk ditabung sebagai cadangan karena dimasa sekarang belum membutuhkan sehingga kelak apabila menginginkan sebuah tindakan sudah memiliki cadangan uang berupa kas 
usaha baru digunakanLaba menjadi salah satu variabel yang diteliti dalam penelitian ini dengan keterkaitannya dengan bantuan modal atau kredit.

Hasil wawancara mendalam menemukan kesimpulan umum dari para UMKM binaan TTIC kadin Jawa Tengah bahwa bantuan/pinjaman modal berpengaruh tidak secara langsung terhadap laba. Laba ditentukan oleh naik turunnnya penjualan. Naik turunnya penjualan ditentukan oleh situasi pasar. Jika UMKM dapat bersaing dengan baik di pasar, maka penjualan meningkat dan pada akhirnya laba meningkat. Bantuan/pinjaman modal berdampak memperlancar usaha-usaha UMKM binaan TTIC Kadin Jawa Tengah untuk memenangkan persaingan.

\section{PENUTUP}

Tambahan modal kerja baik berupa bantuan atau pinjaman diakui oleh UMKM Binaan TTIC Kadin Jawa Tengah memberi dampak yang positif bagi kinerja usaha. Dampak yang dirasakan adalah UMKM memiliki tambahan kemampuan untuk melakukan usaha-usaha dalam memenangkan persaingan sehingga permintaan produknya meningkat, penjualan meningkat dan laba pun meningkat. Dengan demikian dampak tambahan modal berupa bantuan atau pinjaman tidak secara langsung tetapi sangat membantu UMKM untuk meningkatkan kinerja usahanya. Berdasarkan analisis terhadap dampak bantuan /pinjaman modal terhadap kinerja usaha UMKM dapat ditegaskan bahwa bantuan/pinjaman modal bersifat menstimulus atau mendorong upaya-upaya yang dilakukan UMKM untuk meningkatkan kinerja usahanya seperti memperbaiki/menambah peralatan, melakukan inovasi produk, menambah tenaga kerja, menambah persediaan dan melakukan berbagai upaya pemasaran. Penambahan modal pada UMKM perlu disertai dengan pembinaan dan pendampingan secara berkelanjutan supaya UMKM dapat menggunakan bantuan/pinjaman modal dengan efektif. 


\section{DAFTAR PUSTAKA}

Ardianto,Tejo,Barnabas.2014,.Sumber Pendanaan Pada UkM Di Desa Parakan Wetan Temanggung,Skripsi Program S1 Fakultas Ekonomi Universitas Kristen Satya Wacana (dipubikasikan)

Departemen Koperasi dan UMKM Indonesia,www.depkop.go.id

Firdaus, Rahmat, 2004. Manajemen Perkreditan Bank Umum. Bandung : Alfabeta.

Kamus Besar Bahasa Indonesia. [Online]. Tersedia di: http://kbbi.web.id/. Diakses 5 Oktober 2016.

Madjoko,2015,Rumah UMKM -House of SME,Semarang-Kadin Jawa Tengah

Munizu,Musran.2010.Jurnal Manajemen dan Kewirausahaan.www.Idci.dikti.go.id

Purwaningsih,Ratna dan Kusuma,Damar,Pajar,2015,Analisis Faktor-Faktor Yang Mempengaruhi Kinerja Usaha Kecil Dan Menengah Dengan MetodeStructural Equation Modeling,Jurnal Fakultas teknik industri,Universitas Diponegoro

Riyanto, Bambang. 2010. Dasar-Dasar Pembelanjaan Perusahaan, ed. 4, BPFEYOGYAKARTA.

Satori Djam'an, Komariah Aan. 2013. Metode Penelitian Kualitatif. Bandung : Alfabeta 